EDITORIAL

\title{
Inclusivity, Hierarchies, and Culture: Two Neophytes Reflect on the Fourth International Students as Partners Institute
}

David Carless and Connie Yuen-Ying Kwan Faculty of Education, University of Hong Kong

Contact: dcarless@hku.hk yykwanyy@hku.hk

The fourth International Students as Partners Institute (ISaPI) was hosted by the University of Adelaide, Australia from July 10-12, 2019. The institute, previously hosted by McMaster University in Canada, aimed to promote the practice of Students as Partners (SaP) in learning and teaching in higher education. Attendees took part in either a workshop or a change institute to build understanding and develop SaP initiatives.

The institute was our first participation in a SaP event and we participated in the workshop element. We are newcomers to the editorial team of IJSaP as part of the goal of expanding and enriching the cultural diversity of the journal beyond the mainstream English-speaking nations. We have been working together as co-researchers in conducting higher education research, and our recent project investigated feedback practice and feedback cultures in different disciplines. We collaborated in different stages of the research process and observed how staff-student collaboration strengthened the credibility and quality of the research through bringing together different perspectives and expertise.

The aim of this editorial is to use our experiences of participation in the workshop to reflect on some current SaP debates in relation to inclusivity, hierarchy, and culture. In this undertaking, we are revisiting partnership challenges identified in the literature and continuing the path of previous reflections on ISaPI. Acai, Kirby, and Shammas (2017) described their experiences as student facilitators in the inaugural ISaPI event in 2016 and highlighted the role of a culture of trust in encouraging student partners to share their insights in a spirit of open collaboration. Marquis, Black, and Healey (2017) used qualitative data from the same event to illuminate some of the potential benefits and challenges of partnership work, and called for more attention to be given to the different cultural contexts in which participants work. This is largely because power distance, namely the strength of social hierarchies and how power is distributed, may accentuate the challenges of developing fruitful partnerships. Marquis et al. (2019) extended this previous work by interviewing ten participants nine months after the Institute, and found that navigating power dynamics, equity, and inclusion remained prominent in participants' minds well after the event.

The organisation of the rest of the editorial presents our own individual reflections on inclusivity, hierarachy and the role of culture. So that both of our voices can be expressed roughly equally, we use an organisational device of prefacing comments by our Christian names, Connie or David. 


\section{INCLUSIVITY}

Connie: There was an interesting discussion during the workshop on who should be involved in the partnership process in higher education. The majority of us shared the view that a true partnership has to be inclusive, although there were some subtle differences in our perspectives. Some might understand inclusive partnership as including students and staff from as many backgrounds as possible in partnership initiatives. Yet, I conceptualise inclusive partnership as developing an institutional culture that embraces diversity. A truly inclusive partnership might be enhanced by the cultivation of inclusive mindsets within the institutional community.

David: Thinking about inclusivity in the context of the workshop issue enabled me to problematize my current practice. In selecting student partners for my research projects, I have simply been identifying and inviting students who came to my attention due to good performance or recommendations from colleagues. Participation in ISaPI helped me to realize that this was an opportunistic and exclusionary form of selection bias. Yet for an academic, time is precious and user-friendly approaches are attractive. If I am looking for a small number of students to participate in research projects, is it reasonable to reach out primarily to those who I encounter? Would a more inclusionary approach through a general invitation still be practical and cost-effective? Or should I actively seek out diversity?

HIERARCHY

Connie: The success of a partnership, by and large, depends on the level of collaboration between the partners. Working collaboratively is not necessarily new to staff or students, but staff-student partnership is often perceived as challenging. Why do students often enjoy critiquing and debating ideas with peers but not with staff? Institutional hierarchies probably play a major part. Hierarchical difference provides unequal ground for collaboration between staff and students, which subsequently creates constraints on authentic partnership. In this case, shall we acknowledge this as an inherent limitation of staff-student partnership or break down hierarchy to promote genuine partnership? Breaking down existing hierarchies is a major feature of SaP (see e.g., Matthews, 2017).

David: The hierarchy issue also prompted me to reflect on my own practice in relation to our co-research into feedback for student learning. To what extent am I dominating the collaborative research process and downplaying the voices of coresearchers? Or since I am an experienced professor, is it natural and beneficial that I should exhibit research leadership, where appropriate, whilst also acting as a mentor? Should there be more sustained communication between the co-researchers? Yet how feasible is that within our own busy timetables and the challenges of identifying mutually convenient meeting times? Participation in the workshop prompted my reflections on these kinds of issues without, of course, offering any easy solutions.

\section{THE ROLE OF CULTURE}

The third issue that we would like to air at somewhat greater length is that of potential cultural or cross-cultural barriers accentuating challenges of embedding SaP initiatives. It might be the case that in contexts where there is more distance between teachers and students, SaP may be especially hard to implement. Some ISaPI delegates seemed to feel that cultural issues of hierarchy and power might represent a significant challenge for partnership approaches, whereas others felt that these challenges are present 
in all contexts and are just a perennial barrier to be tackled. Given that an aim of staffstudent partnership is to break down some of the hierarchies and barriers to genuine collaboration, to what extent are the power differentials often found, for example, in Southeast Asian societies, a major challenge? This issue is highly pertinent to us because we are based in Hong Kong where power distance is relatively high, and hierarchical relationships between teachers and students may impede the development of SaP. At the same time, close relationships between teachers and students are often developed, and beneath the surface lies Confucian respect for different forms of educational collaboration.

Even a cursory glance at the literature reveals plentiful evidence of SaP work in Southeast Asia, although significantly less than in Anglo-American contexts. Pounder, Ho, and Groves (2016) adopted an ambitious plan deploying student consultants in a scheme involving peer observation of teaching at Lingnan University in Hong Kong. An interesting, but not altogether surprising, finding was that the scheme was more popular with students than staff. Ben Moorhouse and Melanie Oh (2019, this issue) extended partnership in a preservice teacher education programme at the University of Hong Kong into Melanie's first year of teaching in a primary school in Ningbo, China. In a Malaysian case study, teachers partnered successfully with postgraduate students in designing and delivering classroom instruction (Kaur, Awang-Hashim, \& Kaur, 2019). There is also plentiful SaP activity at Nottingham-Ningbo University (see e.g., Sturman et al., 2018), which is an interesting crosscultural context in that most students are Chinese while most staff are not.

Connie: I discussed above how hierarchy affects authentic partnership. A lot of people might then automatically think of the cultural issue: does hierarchy affect the East more than the West? If we look at institutional hierarchical structures, there are actually more similarities than differences among globalised higher education institutions. And if we look at people's behaviours, there are always staff or students who have greater or lesser enthusiasm about SaP regardless of the culture or context. With such diversity within academic communities, could we really identify consistent patterns of cultural influence on SaP developments?

David: I don't believe that national cultures are an insuperable challenge for SaP practices. It may well be the case that different forms of SaP are more suitable for different contexts. What is needed are more examples of partnership developments from areas that are currently under-represented in the literature and more discussion of cross-cultural implementation of SaP. Leaders and others in the SaP movement may continue to reach out to contexts where SaP is under-reported or not yet flourishing. The inclusivity strand of SaP encourages the further expansion of partnership ideas.

To sum up, the cultural and cross-cultural aspects of SaP seem ripe for further investigation. Wendy Green's (2019) reflections on cross-cultural elements of partnership hint at some ongoing possibilities and challenges: "My experience in these partnerships has seemed much like any other cross-cultural encounter, replete with opportunities for misunderstanding as well as for new ways of seeing" (p. 86).

\section{CONCLUSION}

We treasured our participation in the ISaPI institute for the opportunity it afforded us to reflect on issues of inclusivity, hierarchy, and culture. We also appreciate the uniqueness of IJSaP in promoting scholarly publication through the partnership format. Our ongoing contributions are coloured by the competing work priorities that others may also be experiencing. Having completed her undergraduate degree, Connie is beginning her 
teaching career before later embarking on postgraduate study. As a professor in a researchintensive university, David needs to procure competitive research funding and publish his research on feedback for student learning in higher education (Carless, 2019, in press; Winstone $\&$ Carless, 2019). Whatever our futures bring, the collegiality and passion of the ISaPI institute and its participants will remain an enduring memory.

\section{NOTES ON CONTRIBUTORS}

David Carless is a Professor in the Faculty of Education, University of Hong Kong where he specialises in feedback research in higher education.

Connie Yuen-Ying Kwan is a graduate from the Faculty of Education, University of Hong Kong with research interest in educational innovation.

\section{REFERENCES}

Acai, A., Kirby, S., \& Shammas, R. (2017). Reflections on an international "Change Institute" for students as partners: A student perspective. International Journal for Students as Partners, 1(1), 1-7. https://doi.org/10.15173/ijsap.v1i1.3084

Carless, D. (2019, in press). A longitudinal inquiry into students' experiences of feedback: A need for teacher-student partnerships. Higher Education Research and Development.

Green, W. J. (2019). Stretching the cultural-linguistic boundaries of "students as partners." International Journal for Students as Partners, 3(1), 84-88. https://doi.org/10.15173/ijsap.v3i1.3791

Kaur, A., Awang-Hashim, R., \& Kaur, M. (2019). Students' experiences of co-creating classroom instruction with faculty - a case study in eastern context. Teaching in Higher Education, 24(4), 461-477. https://doi.org/10.1080/13562517.2018.1487930

Marquis, E., Black, C., \& Healey, M. (2017). Responding to the challenges of student-staff partnership: The reflections of participants at an international summer institute. Teaching in Higher Education, 22(6), 720-735. https://doi.org/10.1080/13562517.2017.1289510

Marquis, E., Guitman, R., Black, C., Healey, M., Matthews, K. E., \& Dvorakova, L. (2019). Growing partnership communities: What experiences of an international institute suggest about developing student-staff partnership in higher education. Innovations in Education and Teaching International, 56(2), 184-194. https://doi.org/10.1080/14703297.2018.1424012

Matthews, K. E. (2017). Five propositions for genuine students as partners practice. International Journal for Students as Partners, 1(2), 1-9. https://doi.org/10.15173/ijsap.v1i2.3315

Moorhouse, B., \& Oh, M. H. M. (2019). Students as partners beyond formal education: A mentoring partnership in the first year of teaching. International Journal for Students as Partners, 3(2).

Pounder, J. S., Ho, E. H.-I., \& Groves, J. M. (2016). Faculty-student engagement in teaching observation and assessment: A Hong Kong initiative. Assessment \& Evaluation in Higher Education, 41(8), 1193-1205. https://doi.org/10.1080/02602938.2015.1071779 
Sturman, P., Zheng, Y., Peng, L., \& Lamb, D. (2018). Students as partners: The development of an extensive reading programme at the Ningbo campus of the University of Nottingham. Journal of Educational Innovation, Partnership and Change, 4(1), 1-6. https://doi.org/10.21100/jeipc.v4i1.744

Winstone, N. \& Carless, D. (2019). Designing effective feedback processes in higher education: A learning-focused approach. London: Routledge. 